\title{
A Time Series Analysis of Financial Fragility in the UK Banking System
}

\author{
Charles A.E. Goodhart \\ Bank of England, London School of Economics, \\ and Financial Markets Group \\ Pojanart Sunirand \\ Bank of England and \\ London School of Economics \\ Dimitrios P. Tsomocos \\ Bank of England, Said Business School \\ and St. Edmund Hall, University of Oxford, and \\ Financial Markets Group
}

14 September 2004

\begin{abstract}
This paper extends the model proposed by Goodhart, Sunirand, and Tsomocos (2003, $2004 \mathrm{a}, \mathrm{b})$ to an infinite horizon setting. Thus, we are able to assess how the model conforms with the time series data of the U.K. banking system. We conclude that, since the model performs satisfactorily, it can be readily used to assess financial fragility given its flexibility, computability, and the presence of multiple contagion channels and heterogeneous banks and investors.

JEL Classification: C68; E4; E5; G11; G21

Keywords: Financial Fragility; Systemic Risk; U.K. Banking System; Default
\end{abstract}

\section{Introduction}

In a companion paper [Goodhart, Sunirand, and Tsomocos (2004b)], we describe a model to assess risk for banking systems. We have demonstrated that such a model is not only rich enough to incorporate active heterogeneous banks, incomplete markets and endogenous default, but also sufficiently flexible to be calibrated against real UK banking data. In particular, the model comprises of three heterogeneous banks, two of which can be selected to represent any individual banks whereas the third represents the aggregate of the remaining banks in the banking system. We argue, therefore, that the model can, at least in principle, be used as practical procedures for examining the financal stability of banking systems in any country.

However, a limitation of the model presented in Goodhart et al. (2004b) is that it has only two periods. This implies that although it can be calibrated against real data to replicate realistic features of the UK banking system at a specific point in time, its level of complexity is not enough to provide an independent check whether it can capture the main time series properties of these UK banks. The main objective of this paper, therefore, is to extend our model to an infinite-horizon setting, thereby allowing us to investigate empirically how well the simulation results from our extended model can capture the real behaviour of these banks over time. Given that the model is shown to perform well on this front, we argue that it is well-suited as a tool to analyse financial fragility in the UK banking system not only because 
it allows contagion effects between heterogeneous agents to operate actively in equilibrium but also because it can illuminate how such effects may get amplified and propagated over time.

Typicially, standard dynamic models which have an active role for banks assume that the horizon over which rational banks maximise their expected discount profits is infinite. Put differently, bank managers are assumed to behave as if they were shareholders and therefore care about the expected profits over the expected lifetime of the banks. We would, however, argue that, owing to a standard conflict of interest between banks' managers and shareholders, the former may have an incentive to take into account the expected profits of their banks only up to a finite horizon, depending on the number of periods at which they expect to remain in charge of their banks. As will be formally argued in the next section, this is equivalent to assuming that the values of the discount factors of these banks' managers beyond a certain finite horizon become infinitesimally small, i.e. approaching zero. Without loss of generality, we assume for simplicity in our model that such a horizon is equal to one period. So, at the end of period $t$, banks make their optimal decisions on their portfolios to maximise their expected period $t+1$ level of profits. As time approaches the end of period $t+1$, depending on the realisation of the actual state of nature, the outcome from such decisions is realised, which in turn serves as inputs for these banks in making their optimal decisions in the current period. In principle, the horizon over which banks optimise their expected profits can be extended to multiple periods. However, owing to the simple nature of the one-period horizon assumption and, as we shall see, since our simulation results indicate that the time-series properties implied by our model match with those of the real data reasonably well, we shall stick with this assumption throughout the rest of this paper.

As in Goodhart et al. (2004b), given the lack of disaggregated households' and investors' data, we do not explicitly model private agents' optimisating behaviours. Instead, we assume that they are captured by various reduced-form equations relating their actions to a variety of economic variables such as GDP and interest rates, etc. Thus, our model incorporates not only various feedback channels arising from interactions between heterogeneous banks, but also between the banking system and the real economy.

The organisation of the paper is as follows. The next section formally provides a rationale for the argument that banks' managers may choose to maximise their banks' expected profits over a finite horizon. Section 3 presents the model whereas section 4 explains our calibration and simulation methodology. Section 5 then shows the results. Section 6 provides concluding remarks.

\section{Modelling finite-horizon banks' optimisation problem}

This section formally provides an economic justification why the horizon over which bank managers choose to optimise their bank's profits may be finite. Consider a bank's manager who has joined bank $b$ since period 0 . At the end of period $t$, he maximises the bank's expected discounted payoff, which is a quadratic function of profits minus (non-pecuniary) capital violation and default penalties, over the remaining infinite horizon subject to the balance sheet constraint. ${ }^{1}$ The maximisation problem is as follows:

$\max _{\bar{m}_{t}^{b}, \mu_{t}^{b}, d_{t}^{b}, \mu_{d, t}^{b}, v_{t+1}^{b}} E_{t} \sum_{i=0}^{\infty} \beta^{t+i} \Pi_{t+i}^{b}=E_{t} \sum_{i=0}^{\infty} \beta^{t+i}\left[\begin{array}{c}\left(\pi_{t+i}^{b}-c_{s}^{b}\left(\pi_{t+i}^{b}\right)^{2}\right)-\lambda_{k}^{b} \max \left[0, \bar{k}_{t+i}^{b}-k_{t+i}^{b}\right] \\ -\lambda^{b}\left[\mu_{t+i-1}^{b}-v_{t+i}^{b} \mu_{t+i-1}^{b}\right]-\lambda^{b}\left[\mu_{d, t+i-1}^{b}-v_{t+i,}^{b} \mu_{d, t+i-1}^{b}\right]\end{array}\right]$

\footnotetext{
${ }^{1}$ The setting of default and capital violation penalties will be explained in detail in section 3 .
} 
subject to

$$
\begin{gathered}
\bar{m}_{t}^{b}+d_{t}^{b}+A_{t}^{b}=\frac{\mu_{t}^{b}}{\left(1+\rho_{t}\right)}+\frac{\mu_{d, t}^{b}}{\left(1+r_{d, t}^{b}\right)}+e_{t}^{b}+\text { Other }_{t}^{b} \\
v_{t+1}^{b} \mu_{t}^{b}+v_{t+1}^{b} \mu_{d, t}^{b}+\text { Others }_{t}^{b}+e_{t}^{b} \leq v_{t+1}^{h^{b}}\left(1+r_{t}^{b}\right) \bar{m}_{t}^{b}+\left(1+r_{t}^{A}\right) A_{t}^{b}+\widetilde{R}_{t+1} d_{t}^{b}\left(1+\rho_{t}\right)
\end{gathered}
$$

where,

$$
\begin{aligned}
\pi_{t+1}^{b} & =\Delta(3), \\
e_{t+1}^{b} & =e_{t}^{b}+\pi_{t+1}^{b}, \\
k_{t+1}^{b} & =\frac{e_{t+1}^{b}}{\bar{\omega} v_{t+1}^{h^{b}}\left(1+r_{t}^{b}\right) \bar{m}_{t}^{b}+\omega \widetilde{R}_{t+1} d_{t}^{b}\left(1+\rho_{t}\right)+\widetilde{\omega}\left(1+r_{t}^{A}\right) A_{t}^{b}},
\end{aligned}
$$

$\Delta(x) \equiv$ the difference between RHS and LHS of inequality $(x)$,

$c^{b} \equiv$ coefficient of risk aversion in the utility function of bank $b$,

$\lambda_{k}^{b} \equiv$ capital requirements' violation penalties imposed on bank $b$,

$\bar{k}_{t+1}^{b} \equiv$ capital adequacy requirement for bank $b$ in period $t+1$,

$\lambda^{b} \equiv$ default penalties on bank $b$,

$\mu_{t}^{b} \equiv$ amount of money that bank $b$ owes in the interbank market in period $t$,

$d_{t}^{b} \equiv$ bank $b$ 's interbank lending in period $t$,

$\mu_{d, t}^{b} \equiv$ amount of money that bank $b$ owes in the deposit market in period $t$,

$v_{t+1}^{b} \equiv$ repayment rates of bank $b$ to all its creditors in period $t+1$,

$\bar{m}_{t}^{b} \equiv$ amount of credit that bank $b$ extends in the loan market in period $t$,

$A_{t}^{b} \equiv$ the value of market book held by bank $b$ in period $t$,

$e_{t}^{b} \equiv$ amount of capital that bank $b$ holds in period $t$,

$e_{t+1}^{b} \equiv$ amount of capital that bank $b$ holds in period $t+1$,

Other $s_{t}^{b} \equiv$ the 'others' item in the balance sheet of bank $b$,

$r_{t}^{b} \equiv$ lending rate offered by bank $b$ in period $t$,

$r_{d, t}^{b} \equiv$ deposit rate offered by bank $b$ in period $t$,

$\rho_{t} \equiv$ interbank rate in period $t$,

$r_{t}^{A} \equiv$ the rate of return on market book in period $t$,

$v_{t+1}^{h^{b}} \equiv$ repayment rates of agent $h^{b}$ in the loan market in period $t+1$,

$\widetilde{R}_{t+1} \equiv$ the rate of repayment that banks expects to get from its interbank lending in period $t+1$

$\bar{\omega} \equiv$ risk weight on consumer loans,

$\widetilde{\omega} \equiv$ risk weight on market book, and

$\omega \equiv$ risk weight on interbank investment.

We assume that the manager has a particular opportunity cost for working in the bank. He has the option of leaving the bank and seeking alternative employment when he has attained a certain level of profitability. In other words, the manager will be approached by other financial institutions and be offered a better contract (e.g. higher salary) if his existing bank's level of profits is higher than a benchmark level, which we define as $\bar{\pi}$. So, in period $t+i$, if $\pi_{t+i}$ is greater than or equal to the benchmark level, $\pi_{t+i} \geq \bar{\pi}$, the manager will leave the bank for a 
better contract. ${ }^{2}$ However, if $\pi_{t+i}$ is less than the benchmark level, $\pi_{t+i}<\bar{\pi}$, he will remain with the bank. Therefore, the manager's discounted factor associated with period $t+i$ can be described as follows:

$$
\beta^{t+i}=\frac{\beta^{t+i}}{\left(\bar{\pi}-\bar{\pi}_{t+i}\right)} \max \left[\left(\bar{\pi}-\bar{\pi}_{t+i}\right), 0\right]
$$

In period $t+i$, if $\pi_{t+i}<\bar{\pi}$, the manager remains with the bank, implying that the associated discount factor is $\beta^{t+i}$. On the contrary, if $\pi_{t+i} \geq \bar{\pi}$, the manager leaves the bank and therefore will no longer care about the bank's profitability in period $t+i$ and the subsequent periods, i.e. $\beta^{t+i}=\beta^{t+i+1}=\ldots=\beta^{t+\infty}=0$. We are now able to state the following proposition:

Proposition 1 There exist $\lambda^{b} \in(0, \infty]$ and $\lambda_{k}^{b} \in(0, \infty]$ such that the infinite horizon function (1) is equivalent to $E_{t} \sum_{i=0}^{\bar{t}-1} \beta^{t+i} \Pi_{t+i}^{b}$ for some $\bar{t} \in T$.

Proof. The first order condition of the maximisation problem with respect to $v_{t}^{b}$ yields: $\pi_{t}^{b}=\left[1-\lambda^{b}+\frac{\lambda_{k}^{b}}{\bar{\omega} v_{t}^{v^{b}}\left(1+r_{t-1}^{b}\right) \bar{m}_{t-1}^{b}+\omega \widetilde{R}_{t} d_{t-1}^{b}\left(1+\rho_{t-1}\right)+\widetilde{\omega}\left(1+r_{t-1}^{A}\right) A_{t-1}^{b}}\right]$. Thus, by continuity, there exist $\lambda^{b}$ small enough and $\lambda_{k}^{b}$ large enough so that $\pi_{\bar{t}}^{b}>\bar{\pi}$ for some $\bar{t} \in T=\{0,1, \ldots, \infty\}$ since the value of the risk weighted asset $\left[\bar{\omega} v_{t}^{h^{b}}\left(1+r_{t-1}^{b}\right) \bar{m}_{t-1}^{b}+\omega \widetilde{R}_{t} d_{t-1}^{b}\left(1+\rho_{t-1}\right)+\widetilde{\omega}(1+\right.$ $\left.\left.r_{t-1}^{A}\right) A_{t-1}^{b}\right]<+\infty .{ }^{3}$ Recall that $\pi_{t}^{b}$ depends positively on $\lambda_{k}^{b}$ and negatively on $\lambda^{b}$. Therefore, $\beta^{\bar{t}}=\beta^{\bar{t}+1}=\ldots=\beta^{\bar{t}+\infty}=0$. It follows immediately that (1) reduces to $E_{t} \sum_{i=0}^{\bar{t}-1} \beta^{t+i} \Pi_{t+i}^{b}$.

In sum, we have demonstated that, under certain conditions, bank's managers may choose to maximise the expected profits of their existing banks only over a finite horizon since they may depart from these banks for better alternative contracts, or at the latest on retirement. For simplicity, and without loss of generality, we shall assume throughout the remaining of this paper that such a horizon is equal to one period.

\section{The Model}

The model has three heterogeneous banks, $b \in B=\{\gamma, \delta, \tau\}$, four private sector agents, $h \in H=\{\alpha, \beta, \theta, \phi\}$, a Central Bank and a regulator. The time horizon extends over infinite periods, $t \in T=\{1, \ldots, \infty\}$. At each future date, we assume further that there are two possible states of nature, $s \in S=\{i, i i\}$. State $i$ is a normal/good state whereas state $i i$ represents an extreme/crisis event. Moreover, in each period, the probability that state $i$ will occur in the next period is denoted by $p$. As mentioned in the previous section, we assume that the horizon over which banks maximise their expected profits is one period. More specifically, at the end of period $t$, banks maximise their expected period $t+1$ profits, where the expectation is taken over the two possible states.

As in Goodhart et al. (2003, 2004a and b), we assume that individual bank borrowers are assigned during the two periods, by history or by informational constraints, to borrow from a

\footnotetext{
${ }^{2}$ Of course, if the manager departs, another one replaces him and the same argument is repeated. Alternatively, we might have assumed that the bank's policy is reviewed every year at the annual meeting of its board of directors.

${ }^{3}$ The proof that bank's choice variables are bounded away from infinity is contained in Goodhart, Sunirand, and Tsomocos (2003).
} 


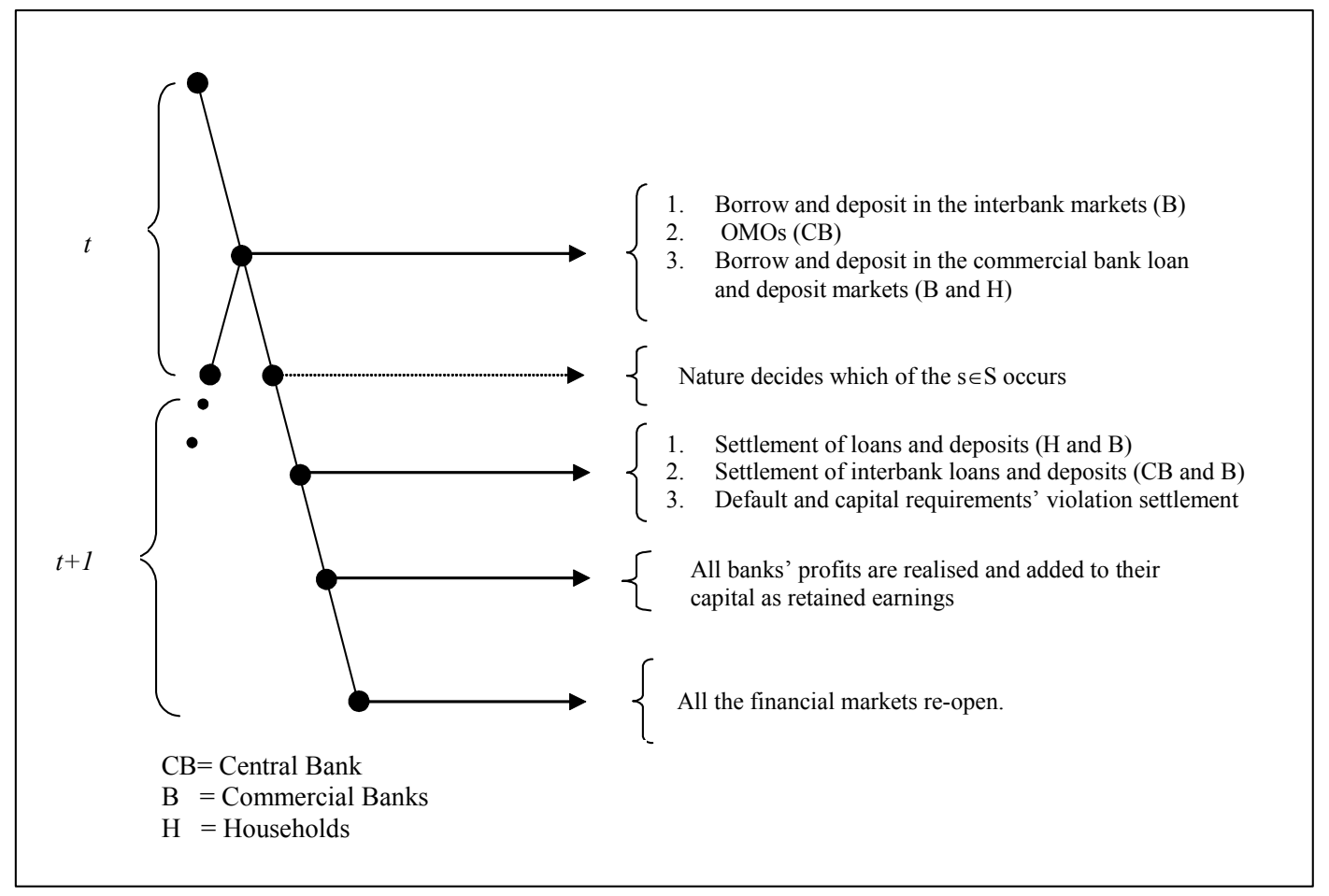

Figure 1: The timeline of the model

single bank (i.e. a limited participation assumption). ${ }^{4}$ Given this assumption, together with our set-up of a system of three heterogeneous banks, we need at least three borrowers. We therefore assume that agents $\alpha, \beta$, and $\theta$ borrow from banks $\gamma, \delta$, and $\tau$, respectively. The remaining agent, Mr. $\phi$, represents the pool of depositors in this economy who supplies funds to every bank. This implies that we have multiple active markets for deposits (by separate bank) and for loans (by borrower and bank). In addition, in each period, we also assume a single, undifferentiated, interbank market where deficit banks are allowed to borrow from surplus banks, and wherein the Central Bank conducts open market operations (OMOs).

The time structure of the model is presented in figure 1. At the end of period $t$, loan, deposit and interbank markets open. Banks decide how much to lend/borrow in each market, expecting rationally any one of the two possible future scenarios to be realised in period $t+1$. Moreover, the Central Bank also conducts OMOs in the interbank market. In the beginning of period $t+1$, depending on the state which actually occurs, all financial contracts signed in the previous period are settled, subject to any defaults and/or capital requirements' violations, which are then penalised. All banks' profits are realised, which are then added as retained earnings to their capital. At the end of the period $t+1$, given the new level of capital, all the financial markets re-opens.

\footnotetext{
${ }^{4}$ In Bhattacharya, Goodhart, Sunirand and Tsomocos (2003), we show that restricted participation in the loan market can also arise as an equilibrium outcome given that the objective functions of banks also include a relative performance criterion, i.e. a preference to outperform their competitors.
} 


\subsection{Banking Sector}

As mentioned, the banking sector comprises three heterogeneous bank, $b \in B=\{\gamma, \delta, \tau\}$, each is distinguished by its unique portfolio deriving from different capital endowment and risk/return preferences. Every bank is assumed to operate under a perfectly competitive environment (i.e. they take all interest rates as exogenously given when making their optimal portfolio decisions). The structure of their balance sheets is given below:

\begin{tabular}{|l|l|}
\hline Assets & Liabilities \\
\hline Loans to agents & Deposits from Mr. $\phi$ \\
Interbank deposits & Interbank borrowing \\
Market book & Equity \\
& Others \\
\hline
\end{tabular}

We assume that all banks endogenise their decisions in the loan, deposit and interbank markets. ${ }^{5}{ }^{6}$ Although we do not model separated bank equity markets, the value of bank capital is endogenous in the model since it represents the amount of capital carried over from the previous period, i.e the amount of capital that banks initially brought to the table plus retained earnings. ${ }^{7}$ The exception, however, is the initial period where we need to start them off with some exogenous capital endowment in order to allow them to begin their operations. The remaining variables are treated as exogenous. ${ }^{8}$ We further assume that banks in our model can default on their financial obligations, subject to default penalties set by the regulator. Thus, by varying the penalties imposed on default from 0 to infinity, we can model $100 \%$ default, no default or an equilibrium level of default between 0 and $100 \% .{ }^{9}$ At first sight, this 'continuous' default rate approach may seem problematic since in reality banks either repay in full at the due date or are forced to close down. However, we interpret a bank's default rate in our model as a probability that such bank chooses to shut down, and hence in the short run to default completely on its financial obligations. For example, a default rate of 4 percent implies that there is roughly a 4 percent chance of a shut down and a 96 percent chance that the bank will repay in full and continue its normal operation. Therefore, a bank's decision to increase its default rates is isomorphic to its decision to adopt a riskier position in pursuit of higher expected profitability. ${ }^{10}$ Finally, as in Bhattacharya et al. (2003), we make a simplifying assumption by assuming that banks' default rates in the deposit and interbank markets are the same, i.e. banks are restricted to repay all their creditors similarly.

Analogous to the modelling of default, banks can violate their capital adequacy requirement, subject to capital requirement violation penalties set by the regulator. In principle, each

\footnotetext{
${ }^{5}$ The modelling of the banking sector follows Shubik and Tsomocos (1992) and Tsomocos (2003a and b).

${ }^{6}$ We note that, in equilibrium, each bank will either be an interbank borrower or lender.

${ }^{7}$ Put differently, we assume that the cost of issuing new capital is prohibitively costly and that banks do not pay any dividend to their shareholders.

${ }^{8}$ Given the present set-up, we cannot endogenise banks' decisions on market book or equity. This is because the model has two states in the second period and one unconstrained asset (i.e. an asset that banks can either go infinitely short or long), which is the interbank market investment. By adding another unconstrained asset, markets would be complete. In principle, our model can be extended to incorporate additional states in the second period and therefore can be used to study the economic effects on the market (trading) book. For example, we can disaggregate the market book into two components according to their riskiness (or rating) and endogenise banks' decisions on these variables. This would allow us to study the endogenous response of risk premia on corporate debt to a series of shocks. However, we face a practical problem on this front since there are insufficient data on the composition of the market book by category, e.g. rating, maturity, and currency.

${ }^{9}$ This modelling of default follows Shubik and Wilson (1977).

${ }^{10}$ For more on this issue, see work in progress by Tsomocos and Zicchino (2004).
} 
bank's effective capital to asset ratios may not be binding, (i.e. their values may be above the regulator's requirement), in which case they are not subject to any capital requirement penalty. However, in our calibration/simulation exercise, we assume for simplicity that each bank wants to keep a buffer above the required minimum, so that there is a non-pecuniary loss of comfort and reputation as capital declines; in this sense the ratios are always binding. Put differently, we assume that banks' self-imposed ideal capital holdings are always above the actual values of all banks' capital to asset ratios. Given this assumption, we can rule out corner equilibria and therefore focus our analysis entirely on well-defined interior solutions whereby banks violate their enhanced capital requirements. Moreover, we assume that penalties are linear as capital declines from its ideal level. Formally, we describe the optimisation problems of these banks below.

\subsubsection{Banks' optimisation problem}

At the end of period $t$, bank $b \in B$ maximises its expected payoff, which is a quadratic function of its expected profitability in the next period minus non-pecuniary penalties that it has to incur if it defaults on its deposit and interbank obligations. It also suffers a capital violation penalty proportional to its capital requirement violation. Expectation is taken rationally over two possible states of nature in period $t+1$. Formally, the optimisation problem of bank $b$ in period $t$ is as follows:

$$
\begin{gathered}
\max _{\bar{m}_{t}^{b}, \mu_{t}^{b}, d_{t}^{b}, \mu_{d, t}^{b}, v_{t+1, s}^{b}, s \in S} E_{t}\left(\Pi_{t+1}^{b}\right)=\sum_{s \in S} p_{s}\left[\frac{\pi_{t+1, s}^{b}}{10^{10}}-c_{s}^{b}\left(\frac{\pi_{t+1, s}^{b}}{10^{10}}\right)^{2}\right] \\
-\sum_{s \in S} p_{s}\left[\lambda_{k s}^{b} \max \left[0, \bar{k}_{t+1, s}^{b}-k_{t+1, s}^{b}\right]+\frac{\lambda_{s}^{b}}{10^{10}}\left[\mu_{t}^{b}-v_{t+1, s}^{b} \mu_{t}^{b}\right]+\frac{\lambda_{s}^{b}}{10^{10}}\left[\mu_{d, t}^{b}-v_{t+1, s}^{b} \mu_{d, t}^{b}\right]\right]
\end{gathered}
$$

subject to

$$
\begin{gathered}
\bar{m}_{t}^{b}+d_{t}^{b}+A_{t}^{b}=\frac{\mu_{t}^{b}}{\left(1+\rho_{t}\right)}+\frac{\mu_{d, t}^{b}}{\left(1+r_{d, t}^{b}\right)}+e_{t}^{b}+\text { Other }_{t}^{b} \\
v_{t+1, s}^{b} \mu_{t}^{b}+v_{t+1, s}^{b} \mu_{d, t}^{b}+\text { Other }_{t}^{b}+e_{t}^{b} \leq v_{t+1, s}^{h^{b}}\left(1+r_{t}^{b}\right) \bar{m}_{t}^{b}+\left(1+r_{t}^{A}\right) A_{t}^{b}+\widetilde{R}_{t+1, s} d_{t}^{b}\left(1+\rho_{t}\right), s \in S
\end{gathered}
$$

where,

$$
\begin{aligned}
\pi_{t+1 s}^{b} & =\Delta(6) \\
e_{t+1, s}^{b} & =e_{t}^{b}+\pi_{t+1, s}^{b}, s \in S \\
k_{t+1, s}^{b} & =\frac{e_{t+1, s}^{b}}{\bar{\omega} v_{t+1, s}^{h^{b}}\left(1+r_{t}^{b}\right) \bar{m}_{t}^{b}+\omega \widetilde{R}_{t+1, s} d_{t}^{b}\left(1+\rho_{t}\right)+\widetilde{\omega}\left(1+r_{t}^{A}\right) A_{t}^{b}}, s \in S
\end{aligned}
$$

$p_{s} \equiv$ probability that state $s \in S$ will occur,

$c_{s}^{b} \equiv$ coefficient of risk aversion in the utility function of bank $b \in B$, 
$\lambda_{k s}^{b} \equiv$ capital requirements' violation penalties imposed on bank $b \in B$ in state $s \in S$,

$\bar{k}_{t+1, s}^{b} \equiv$ capital adequacy requirement for bank $b \in B$ in period $t+1$ if state $s \in S$ occurs,

$\lambda_{s}^{b} \equiv$ default penalties on bank $b \in B$ in state $s \in S$,

$v_{t+1, s}^{b} \equiv$ repayment rates of bank $b \in B$ to all its creditors in period $t+1$ if state $s \in S$ occurs,

$e_{t+1, s}^{b} \equiv$ amount of capital that bank $b \in B$ holds in period $t+1$ if state $s \in S$ occurs,

$v_{t+1, s}^{h^{b}} \equiv$ repayment rates of agent $h^{b} \in H^{b}=\left\{\alpha^{\gamma}, \beta^{\delta}, \theta^{\tau}\right\}$ to his nature-selected bank $b \in B$ in the loan market in period $t+1$ if state $s \in S$ occurs,

$\widetilde{R}_{t+1, s} \equiv$ the rate of repayment that banks expects to get from its interbank lending in period $t+1$ if state $s \in S$ occurs.

Equation (5) implies that, at the end of period $t$, the assets of bank $b \in B$, which consist of its credit extension, interbank lending, and market book investment, must be equal to its liabilities obtained from interbank and deposit borrowing and its equity, where 'Other $s^{b}$, represents the residual. Equations (6) and (7) then show that, dependent on which of the $s \in S$ actually occurs, the profit that bank $b$ incurs in the next period is equal to the difference between the amount of money that it receives from its asset investment and the amount that it has to repay on its liabilities, adjusted appropriately for default in each market. As shown in equation (8), the profit earned is then added to its initial capital, which in turn becomes its capital in period $t+1$. Finally, equation (9) implies that the capital to asset ratio of bank $b$ in period $t+1$ if state $s \in S$ occurs is equal to the corresponding ratio of capital to the risk-weighted assets.

\subsection{Central Bank and Regulator}

The Central Bank's and the regulator's decisions are exogenous. The Central Bank and the regulator may, but need not, be a single institution. The Central Bank conducts monetary policy by engaging in open market operations in the interbank market. We assume that, in each period, the Central Bank sets the interbank rate as its monetary policy instrument. In doing so, it can either supply base money, $M_{t} \geq 0$, or issue government bond, $\bar{B}_{t} \geq 0$, but not both at the same time, to clear the interbank market.

The regulator sets capital adequacy requirements in state $s \in S$ of the next period for all banks $\left(\bar{k}_{t+1, s}^{b}, b \in B\right)$ as well as imposes penalties on their failures to meet such requirements $\left(\lambda_{k s}^{b}, b \in B, s \in S\right)$ and on default on their financial obligations in the deposit and interbank markets $\left(\lambda_{s}^{b}, b \in B, s \in S\right)$. Finally, he also sets the risk weights on consumer loan, interbank and market book investment $(\bar{\omega}, \omega, \widetilde{\omega})$.

\subsection{Private agent sector}

In each period, household borrower $h^{b}, h^{b} \in H^{b}=\left\{\alpha^{\gamma}, \beta^{\delta}, \theta^{\tau}\right\}$, demands consumer loans from his nature-selected bank $b$ and chooses the default rate on his loans for each of the two possible states, $s \in S$, in the next period. The remaining agent, Mr. $\phi$, supplies his deposits to each bank $b \in B$. As mentioned, we do not explicitly model the optimisation problems of households. The reason is that it is very difficult, if at all possible, to find real disaggregated data for private agent sectors, e.g. the monetary and goods endowment of each banks's borrowers and depositors. This latter is particularly important since one of the key objectives of this paper is take our model to real data. So, instead of explicitly providing microfoundations for households' decisions, we endogenise them by assuming the following reduced-form equations. 


\subsubsection{Household Borrowers' Demand for Loans}

Because of the limited participation assumption in every consumer loan market, each household's demand for loans in period $t$ is a negative function of the corresponding lending rate offered by his nature-selected bank. In addition, his demand for loans also depends positively on the expected GDP in the subsequent period. Put differently, we implicitly assume that household borrowers rationally anticipate GDP in both states of the next period, which then determines their expected future income, and adjust their loan demand in this period accordingly in order to smooth their consumption over time. As in Goodhart et al. (2003, 2004a and b), our money demand function manifests the standard Hicksian elements whereby it responds positively to current and expected income and negatively to interest rates. Finally, in order to improve the empirical fit, we introduce a linear time trend in each household borrower's loan demand function. As will be explained in the next section, the UK banking data that we use in our calibration exercise is from 1997-2003. So, we define a linear time trend variable 'trend', which has the value of 0 in 1997, 1 in 1998, and so on.

Specifically, we assume the following functional form for household $h^{b}$ 's loan demand in period $t$ from his nature-selected bank $b, \forall h^{b} \in H^{b}$, and $b \in B$ :

$$
\ln \left(\mu_{t}^{h^{b}}\right)=a_{h^{b}, 1}+a_{h^{b}, 2} \text { trend }+a_{h^{b}, 3} \ln \left[p\left(G D P_{t+1, i}\right)+(1-p) G D P_{t+1, i i}\right]+a_{h^{b}, 4} r_{t}^{b}
$$

where,

$\mu_{t}^{h^{b}} \equiv$ amount of money that agent $h^{b} \in H^{b}$ chooses to owe in the loan market of bank $b \in B$ in period $t$, and

$G D P_{t+1, s} \equiv$ Gross Domestic Product in period $t+1$ if state $s \in S$ occurs.

\subsubsection{Mr. $\phi$ 's Supply of Deposits}

Unlike the loan markets, we do not assume limited participation in the deposit markets. This implies that Mr. $\phi$ can choose to diversify his deposits with every bank. Thus, Mr. $\phi$ 's deposit supply with bank $b$ in period $t$ depends not only on the corresponding deposit rate offered by bank $b$ but also on the rates offered by the other banks. Moreover, since banks in our model can default on their deposit obligations, the expected rate of return on deposit investment of Mr. $\phi$ with bank $b$ has to be adjusted appropriately for its corresponding expected default rate. Finally, Mr. $\phi$ 's deposit supply is a positive function of the expected GDP in the subsequent period.

In sum, since his deposit decisions determine his investment portfolio, given the expected rates of return, he diversifies among the existing deposit markets. Mr. $\phi$ 's deposit supply function with bank $b, \forall b \in B$, in period $t$ is as follows:

$$
\begin{aligned}
\ln \left(d_{b, t}^{\phi}\right)= & z_{b, 1}+z_{b, 2} \ln \left[p\left(G D P_{t+1, i}\right)+(1-p) G D P_{t+1, i i}\right]+z_{b, 3}\left[r_{d, t}^{b}\left(p v_{t+1, i}^{b}+(1-p) v_{t+1, i i}^{b}\right)\right] \\
& +z_{b, 4} \sum_{\dot{b} \neq b \in B}\left[r_{d, t}^{\hat{b}}\left(p v_{t+1, i}^{\hat{b}}+(1-p) v_{t+1, i i}^{\hat{b}}\right)\right]
\end{aligned}
$$

where,

$d_{b, t}^{\phi} \equiv$ amount of money that agent $\phi$ chooses to deposit with bank $b \in B$ in period $t$. 


\subsubsection{Households' Loan Repayment Rates}

We assume that each household's repayment rate on his loan obligation to his nature-selected bank for each of the two possible states of period $t+1, s \in S$, is a positive function of the corresponding GDP level as well as the aggregate credit supply available in the previous period. The latter variable captures the effect of 'credit crunch' in the economy whereby a fall in the overall credit supply in the economy aggravates the default probability of every household. ${ }^{11}$ Specifically, the functional form of the repayment rate of household $h^{b}, \forall h^{b} \in H^{b}$, to his nature-selected bank $b \in B$, in state $s \in S$ of period $t+1$ is as follows:

$$
\ln \left(v_{t+1, s}^{h^{b}}\right)=g_{h^{b}, s, 1}+g_{h^{b}, s, 2} \ln \left(G D P_{t+1, s}\right)+g_{h^{b}, s, 3}\left[\ln \left(\bar{m}_{t}^{\gamma}\right)+\ln \left(\bar{m}_{t}^{\delta}\right)+\ln \left(\bar{m}_{t}^{\tau}\right)\right]
$$

\subsection{GDP}

GDP in each state of period $t+1$ is assumed to be a positive function of the aggregate credit supply available in the previous period. Since the Modigliani-Miller proposition does not hold in our model ${ }^{12}$, higher credit extension as a result of loosening monetary policy, or any other shocks, generates positive effects, e.g. a real balance effect, that raises consumption demand and ultimately GDP. Finally, we introduce a linear time trend to improve the empirical fit. The following functional form for GDP in state $s \in S$ of period $t+1\left(G D P_{t+1, s}\right)$ holds:

$$
\ln \left(G D P_{t+1, s}\right)=u_{s, 1}+u_{s, 2} \text { trend }+u_{s, 3}\left[\ln \left(\bar{m}_{t}^{\gamma}\right)+\ln \left(\bar{m}_{t}^{\delta}\right)+\ln \left(\bar{m}_{t}^{\tau}\right)\right]
$$

\subsection{Market Clearing Conditions}

There are seven active markets in the model (three consumer loan, three deposit and one interbank markets). Each of these markets determines an interest rate that equilibrates demand and supply in equilibrium. ${ }^{13}$

$$
\begin{aligned}
1+r_{t}^{b} & =\frac{\mu_{t}^{h^{b}}}{\bar{m}_{t}^{b}}, h^{b} \in H^{b}, \forall b \in B \\
1+r_{d, t}^{b} & =\frac{\mu_{d, t}^{b}}{d_{b, t}^{\phi}}, \forall b \in B \\
1+\rho_{t} & =\frac{\bar{B}_{t}+\sum_{b \in B} \mu_{t}^{b}}{M_{t}+\sum_{b \in B} d_{t}^{b}}
\end{aligned}
$$

We note that these interest rates, i.e. $r_{t}^{b}, r_{d, t}^{b}$, and $\rho_{t}, b \in B$, are the ex ante nominal interest rates that incorporate default premium since default is permitted in equilibrium. Their effective (ex post) interest rates have to be suitably adjusted to account for default in their corresponding markets. ${ }^{14}$

\footnotetext{
${ }^{11}$ Higher interest rates, given that households are liquidity constrained, ultimately increase their debt obligations in the future. Hence, defaults rise.

${ }^{12}$ See Goodhart et al. (2003) for an extensive discussion.

${ }^{13}$ The interest rate formation mechanism is identical to the offer-for-sale mechanism in Dubey and Shubik (1978). The denominator of each of the expressions (14-16) represents the supply side whereas the numerator divided by $(1+r), r \in\left\{r^{b}, r_{d}^{b}, \rho\right\}, b \in B$ corresponds to the demand. Note that this interest rate formation mechanism is well-defined both in, and out of, equilibrium.

${ }^{14}$ For more on the method of calculating the ex post interest rates, see Shubik and Tsomocos (1992).
} 


\subsection{Equilibrium}

Let $\sigma^{b}=\left\{\bar{m}_{t}^{b}, \mu_{t}^{b}, d_{t}^{b}, \mu_{d, t}^{b}, v_{t+1, s}^{b}, \pi_{t+1, s}^{b}, e_{t+1, s}^{b}, k_{t+1, s}^{b}\right\} \in R_{+} \times R_{+} \times R_{+} \times R_{+} \times R_{+}^{2} \times R^{2} \times R^{2} \times R^{2}$ for $b \in B ; \sigma^{h^{b}} \equiv\left(\mu_{t}^{h^{b^{\prime}}}, v_{t+1, s}^{h^{b}}\right) \in R_{+} \times R_{+}^{2}$ for $h^{b} \in H^{b}$ and ; $\sigma^{\phi} \equiv\left(d_{b}^{\phi}\right) \in R_{+}$for $b \in B$; and $G D P_{t+1, s} \in R^{2}$. Also, let $\eta \in\left\{r_{t}^{\gamma}, r_{t}^{\tau}, r_{t}^{\delta}, r_{d, t}^{\gamma}, r_{d, t}^{\tau}, r_{d, t}^{\delta}, M_{t}, \bar{B}_{t}\right\}, B^{b}(\eta)=\left\{\sigma^{b}:(5)-(9)\right.$ hold $\}$. We say that $\left(\left(\sigma^{b}\right)_{b \in B}, \eta,\left(\sigma^{h^{b}}\right)_{h^{b} \in H^{b}}, \sigma^{\phi},\left(G D P_{t+1, s}\right)_{s \in S}\right)$ is a monetary equilibrium with commercial banks and default for the economy

$$
E\left\{\left(e_{t}^{b}, \text { Others }^{b}, A^{b}\right)_{b \in B} ; p ;\left(\bar{k}_{t+1, s}^{b}, \lambda_{s}^{b}, \lambda_{k s}^{b}, \bar{\omega}, \omega, \widetilde{\omega}\right)_{b \in B, s \in S} ; r_{t}^{A} ; \rho\right\}
$$

iff:

(i) $\sigma^{b} \in \underset{\sigma^{b} \in B^{b}(\eta)}{\operatorname{Argmax}} E_{t}\left(\Pi_{t+1}^{b}\left(\pi_{t+1}^{b}\right)\right), b \in B$

(i.e. all banks optimise.)

(ii) All markets (14)-(16) clear.

(iii) $\widetilde{R}_{s}=\frac{\sum_{b \in B} v_{t+1 s}^{b} \mu_{t}^{b}}{\sum_{b \in B} \mu_{t}^{b}}, s \in S$

(i.e. All banks are correct in their expectation about the repayment rates that they gets from their interbank lending.)

We emphasise here that the equilibrium conditions $(i)-($ iii $)$ are consistent with the defining properties of a competitive equilibrium with rational expectations.

(iv) $\sigma^{h^{b}}, \sigma^{\phi}$ and $G D P_{t+1, s}$, for $h \in H$ and $s \in S$ satisfy the reduced-form equations (10)-(13).

(i.e. loan demand, deposit supply, repayment rates, and GDP in both states satisfy the reduced-form equations (10)-(13).)

\section{Calibration and Simulation Methodology: The UK banking sector}

In this section we demonstrate how the model developed in the previous section can be applied to simulate the behaviour of UK banks over time. The analysis is based primarily on the annual account data of UK banks, which are available from 1997 to 2003 . We assume that the banking sector comprises of seven largest UK banks measured in terms of their total assets as at end of 2003 (i.e. Abbey National, Barclays, HBOS, HSBC, Lloyds, Royal Bank of Scotland, Standard Chartered) and other major banks which have either been merged with or acquired by these seven banks over the sample period (i.e. Nat West, Bank of Scotland, and Halifax). ${ }^{15}$ We have chosen banks $\gamma$ and $\delta$ to represent specifically two of these banks which have never

\footnotetext{
${ }^{15}$ During 1997-2003, there have been two major mergers and acquisitions (M\&A) between UK banks. In March 2000, Royal Bank of Scotland acquired Nat West. In September 2001, Halifax and Bank of Scotland merged and since then has become HBOS. Other minor M\&As include, for example, the acquisition of Woolwich by Barclays in 2000. However, due to the lack of market book data for Woolwich and that the size of Woolwich is relatively small compared to that of Barclays at the time of acquisition, we ignore this M\&A.
} 
encountered any merger and acquisition over the sample period. However, owing to the data confidentiality reason, we do not reveal their identities. Bank $\tau$ then represents the aggregate of the remaining active banks in the banking sector at each point in time. For example, Nat West is considered as part of bank $\tau$ only from 1997 to 1999, after which it no longer exists as it was acquired by Royal Bank of Scotland in March 2000.

To simulate the time-series property of UK banks, the following subsection explains how we first calibrate our model against the real data to capture realistic features of the UK banking sector as at the end of 1997, the period from which the data became available. Taking this as the starting point, subsection 4.2 then describes how we employ our model to simulate the behaviour of these UK banks in the subsequent periods, thereby allowing us to assess how their positions in the loan, deposit, and interbank markets endogenously evolve over time.

\subsection{Calibration}

Our calibration procedure follows directly that presented in Goodhart, Sunirand, and Tsomocos (2004b). In each period $t$, excluding the Lagrange multipliers, conditions $(i)-(i v)$ in the previous section imply that we have a system of 56 equations in 143 unknown variables, 87 of which are exogenous variables/parameters in the model. ${ }^{16}$ This implies that there are 87 variables whose values have to be chosen in order to obtain a numerical solution to the model. Thus, they represent the degrees of freedom in the system and can either be set appropriately or calibrated against the real data. In particular, we choose the values of these variables such that they capture realistic features of the UK banking sector in 1997. It is important to note that these variables, which are exogenous when solving the system of equations, do not necessarily have to be those which are exogenous in the model. ${ }^{17}$ We report the values of exogenous parameters/variables in the model and the resulting initial equilibrium in table I. The table also summarises whether the value of each variable reported is (1) calibrated against real data, (2) arbitrarily selected, or (3) endogenously solved. We note, however, that, owing to the data confidentiality reason, we suppress those numbers which are based on the calibrated balance sheet data of UK banks and replace them by ' $x x x$ '. Unless stated otherwise, the values of all the nominal variables reported therein, e.g. all bank balance sheet items, are normalised by $10^{10}$.

\footnotetext{
${ }^{16}$ As mentioned, banks are endowed with some capital in the initial period. Thus it is an exogenous variable in the model. However, as will be discussed in the next subsection, bank capital becomes endogenous in the subsequent periods.

${ }^{17}$ For example, the Central Bank in our model fixes the interbank interest rate and lets base money adjust endogenously. However, we can first choose the value of base money and let the system of equations determine endogenously the value of the interbank rate that supports the preset value of base money.
} 


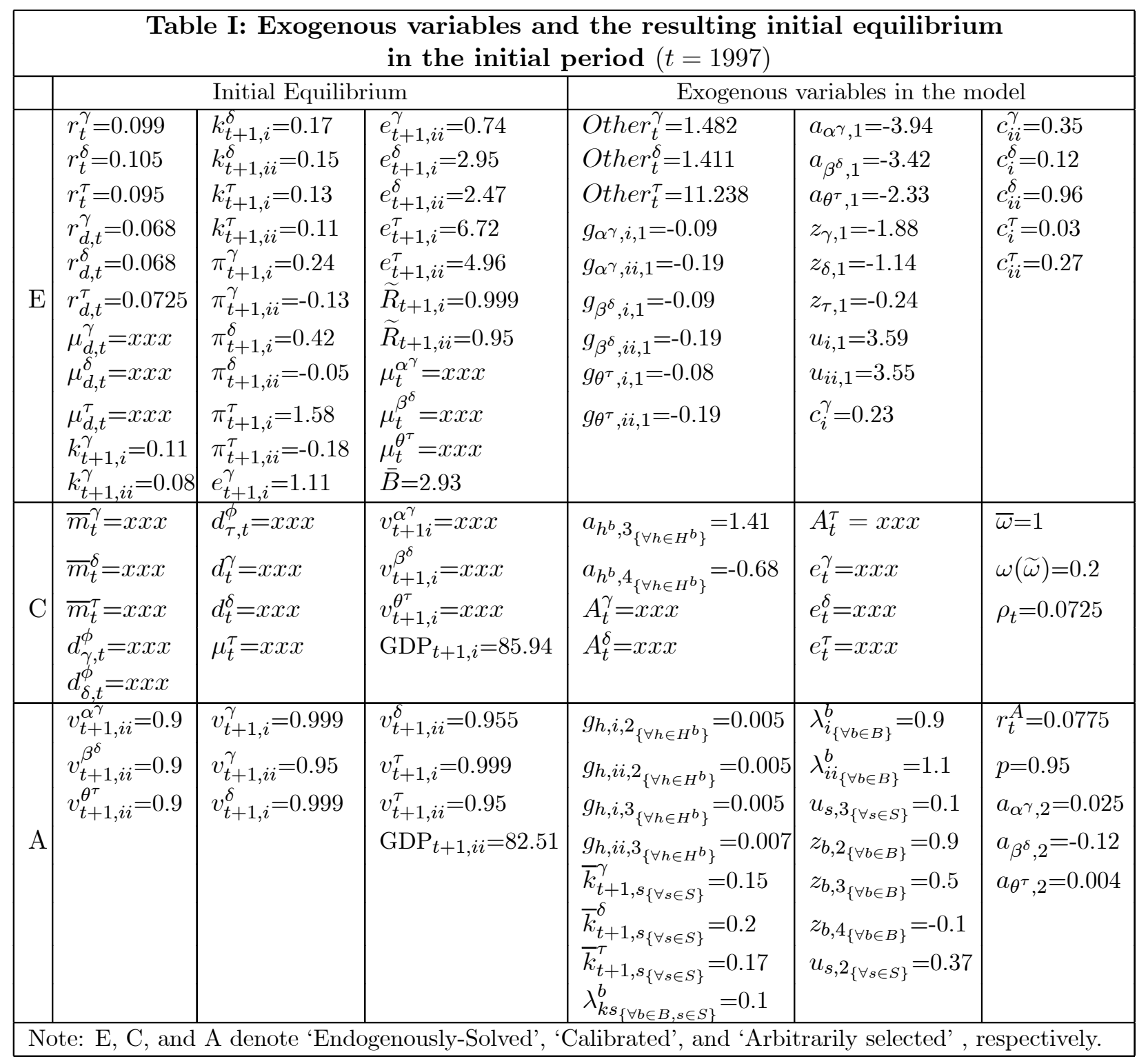

The values of all banks' balance sheet items in the initial period, $t=1997$, i.e. $\left\{\bar{m}_{t}^{b}, \mu_{d, t}^{b}\right.$, Other $\left.s_{t}^{b}, A_{t}^{b}, \mu_{t}^{b}, d_{t}^{b}, e_{t}^{b}\right\}_{b \in B}$, are calibrated using the annual account data for UK banks as at the end of 1997. We note that, at this point in time, banks $\gamma$ and $\delta$ are net lenders whereas bank $\tau$ is a net borrower in the interbank market. ${ }^{18}$ Based on the same source of data, we calibrate the values of private agents' loan repayment rates to their nature-selected banks in the good/normal state of the next period, i.e. $\left(v_{t+1, i}^{h^{b}}\right)_{\left\{h^{b} \in H^{b}\right\}}$, using each bank b's ratio of provision at the end of 1998 to the corresponding value of total customer loans. However, since there are no data available for crisis/extreme events, the default rates of all private agents in the bad state (state $i$ ) are arbitrarily set to 0.1 .

The probability that state $i i$ will occur, $1-p$, is chosen to be 0.05 , given that it reflects an extreme event. Since banks rarely default on their debt obligations in the good state, the corresponding repayment rates in the deposit and interbank markets for all banks in the next

\footnotetext{
${ }^{18}$ Specifically, for $t=1997, \mu_{t_{b \in\{\gamma, \delta\}}}^{b}=0, d_{t_{b \in\{\gamma, \delta\}}}^{b}>0, \mu_{t}^{\tau}>0$, and $d_{t}^{\tau}=0$.
} 
period, i.e. $v_{t+1, i}^{b}, b \in B$, are set to 0.999 . In state $i i$, the bad state, we arbitrarily set the analogous repayment rates to 0.95 for bank $\tau$ and 0.955 for banks $\gamma$ and $\delta$. These values are selected to be relatively higher compared with households' repayment rates in state ii $(0.9)$ since in reality the probability that banks would default on their financial obligations is smaller than that of households. Note also that the chosen value for banks $\gamma$ 's and $\delta$ 's repayment rates is slightly greater than that of bank $\tau$ because their deposit rates, whose values are determined endogenously, are slightly smaller in equilibrium. This may suggest at first glance that we are assuming what we need to estimate, i.e. a bank's willingness to run a risky position, which could lead to enforced shut down. Not quite so, since each chosen value for a bank's chosen default rate relates to an equivalent subjective default penalty. If you give us, the model builders, some guidance on banks' aversion to default penalties, i.e. the size of the $\lambda_{s}^{b}, b \in B, s \in S$, we can adjust the default probabilities accordingly.

We choose the value of the interbank interest rate, $\rho_{t}$, to be 7.25 percent to match with the actual value of UK Repurchase (RP) rate in December 1997. The value of risk weight for loans is set to 1 whereas the corresponding values for market book and interbank lending are 0.2. The values of capital to asset requirement set by the regulator for banks in both states of the next period $\left(\bar{k}_{t+1, s}^{b}, b \in B, s \in S\right)$ is chosen to be slightly higher, but almost equal to, their corresponding value in state $i$ so that all banks always violate their capital requirement. ${ }^{19}$

The values of default and capital violation penalties $\left(\lambda_{s}^{b}\right.$ and $\left.\lambda_{k s}^{b}, b \in B, s \in S\right)$ reflect both the tightness of the regulator's regulatory policy and the (subjective) aversion of banks' managements to putting themselves at risk of default and/or regulatory violations, and can, in principle, be treated as inputs given by the practitioner users of this model. Their values are, however, unobservable and therefore have to be chosen somehow. We have chosen them in this example to be consistent with the following outcomes. First, the resulting endogenously-solved banks' lending rates are such that all banks earn positive profit in state $i$, whereas they suffer a loss in state $i i$. This in turn implies that banks' capital in the next period (1998) deteriorates if the bad state (ii) occurs. Second, all banks' coefficients of risk aversion $\left(c_{s}^{b}, b \in B, s \in S\right)$ are positive, implying that banks' utility functions are well-behaved, i.e. concave. Lastly, the rate of return on market book is arbitrarily chosen to be 7.75 percent, i.e. 50 basis points higher than the interbank rate.

We calibrate the value of GDP in the good state of the next period to match with the actual UK (annual) GDP in 1998. We set the value of GDP in the bad state to represent a $4 \%$ fall from its corresponding value in the good state. The values of coefficients $a_{h^{b}, 3}$ and $a_{h^{b}, 4}$, $\forall h^{b} \in H^{b}$, in the reduced-form equation (10) are calibrated, respectively, using the values of the long-run income and interest rate elasticities of UK household sector estimated by Chrystal and Mizen (2001). Moreover, the coefficient values of the time trend, $a_{h^{b}, 2}, \forall h^{b} \in H^{b}$, are chosen appropriately to improve the empirical fit. Given the limited participation assumption in the loan markets, the difference in these values reflect the variation in the rate of growth of each borrowing group's demand for loans.

To our knowledge, we do not know any empirical study which estimates deposit supply and default probability functions for UK household/private sectors. Although this can, in principle, be done, such an exercise is beyond the scope of this paper. So, we arbitrarily choose the appropriate values of $z_{b, 2}, z_{b, 3}, z_{b, 4}, \forall b \in B$, in equation (11), and the values of $g_{h^{b}, s, 2}$ and

\footnotetext{
${ }^{19}$ As mentioned in section 3.1, this is a simplifying assumption. Recall that capital requirements' violation penalty enters banks' objective functions as ' $\max \left[0, \bar{k}^{b}-k_{s}^{b}\right]$ '. However, given our assumption that banks always violate their capital requirement, we can restrict the optimisation problem to $\bar{k}^{b}-k_{s}^{b}>0$, thus avoiding 'corner' equilibria.
} 
$g_{h^{b}, s, 3}, \forall h^{b} \in H^{b}, s \in S$, in equation (12). As can be seen from table I, the values of $g_{h^{b}, i, 3}$ is chosen to be greater than the corresponding values of $g_{h^{b}, i i, 3}, \forall h^{b} \in H^{b}$, implying that the effect of a 'credit crunch' is assumed to be stronger in the bad state.

The remaining parameters for which their values have to be chosen are the coefficients $u_{s, 2}$, and $u_{s, 3}, \forall s \in S$, in the reduced-form equation (13). We set the value of the latter to be equal to 0.1. Finally, in order to improve the empirical fit, the value of the coefficients of the time trend in the reduced form GDP functions is set to 0.37 .

Given the chosen values of the variables mentioned above, we are left with the system of 56 equations in 56 unknown variables. By solving such system, the values of all the remaining variables are specified and a numerical solution to the model is obtained.

\subsection{Simulation}

As mentioned, in each period, banks in our model choose their loan supply, deposit demand, interbank lending/borrowing, and default rates as their endogenous variables to maximise their expected payoff in the next period, where the expectation is taken over the two possible states of nature. The optimisation problem takes as given the values of various exogenous parameters/variables in the model, as shown in table I. So, in order to simulate how UK banks endogenously change their optimal position in various markets over time, these values have to be specified. We do so as follows:

We have chosen the values of various exogenous variables which are unobservable in practice such as the coefficients in the banks' utility functions, default and CAR violation penalties to be same as their corresponding values in the initial period (1997). Since the values of the coefficients in the banks's utility functions are chosen such that they support the actual calibrated values of banks' balance sheet position in 1997, they arguably represent these banks' risk-return preferences at the time.

Since our model does not endogenise the market investment book and 'others' item in bank balance sheets, we also need to specify their values. We do so by calibrating them against the real data in each period. Moreover, because the interbank rate serves as the Central Bank's monetary policy instrument in this model, we calibrate its values over the period using the real data on UK RP rate at the end of each of the sample year. As in our initial period, the rate of return on market book investment in each of the subsequent periods is then assumed to be 50 basis points higher than the corresponding interbank rate.

As mentioned, because 1997 is our initial period, banks are endowed with some level of capital, i.e. for $t=1997, e_{t_{\{\forall b \in B\}}}^{b}$ are exogenous in the model. However, in the subsequent periods, bank capital becomes endogenous in the model. In particular, it is equal to the amount that these banks initially brought to the table from the previous period plus any retained earnings, where the actual value of the latter depends on the realisation of one of the two possible states, $s \in S$. This crucially implies that the outcome from each bank's optimal decisions in each period can directly affect its own as well as the other banks' decisions in the subsequent periods via their influence on accumulated bank capital. Since the UK financial sector has been exceptionally sound over the sample period, we assume that the good state, state $i$, has always been the actual realisation in each of the subsequent periods.

Given that the values of all the exogenous variables in the model are determined in each of the period between 1998 to 2003 and that the corresponding value of bank capital is endogenised, we are able to simulate the values of all banks' choice variables over the sample period, thereby allowing us to explore how these banks optimally change their positions in various financial markets over the sample periods. In the next section, we show our simulation 
result.

\section{Results}

Figure 2 shows our simulation results and, where applicable, compares them with the real data. Due to data confidentiality reasons, we cannot show the results for the two individual banks $(\gamma$ and $\delta)$ and only present the results for bank $\tau$. We note, however, that the result for bank $\tau$ in terms of its ability to track the real data over the sample period is generally a reasonably good representation of that of the other two banks. ${ }^{20}$

As can be seen from the figure, the values of bank $\tau$ 's market book, 'others', and the interbank rate, all of which are exogenous in the model, are calibrated against real data throughout the sample period. Our calibration procedure to generate realistic behaviour patterns for the UK banks in the initial period implies that the simulated series for bank $\tau$ 's loans, deposits, and capital as well as Mr. $\theta$ 's repayment rate and GDP in the good state start off from exactly the same points as their corresponding real data series. In the subsequent periods, we observe that the simulated series for bank $\tau$ 's loans, deposits and interbank borrowing exhibit an upward trend, all of which track the real data reasonably well. This is primarily driven by the observed downward trend of the interbank rate which represents the Bank of England's accommodating monetary policy over the sample period. Given a cheaper cost of interbank borrowing, other things constant, bank $\tau$ borrows more from the interbank market and transfers these extra liquidity to the loan market by extending more credit to Mr. $\theta$. Thus, we observe a downward trend on the simulated lending rate series. Moreover, given higher aggregate credit supply in the economy, GDP in the following period rises. This underpins the observed upward trend for the simulated GDP series which is almost identical to that observed in real data. Anticipating higher GDP in the next period, household borrower (Mr. $\theta$ ) repays more to bank $\tau$ in order to reduce the extent of default penalties. Moreover, Mr. $\phi$ supplies more deposits with bank $\tau$, generating the observed downward trend in the deposit rate. In fact, the implied pattern of the lending and deposit rates mimic that of the interbank market very closely.

Even though the simulated series for bank $\tau$ 's net interbank borrowing exhibits a realistic upward trend, it evidently appears to be quite volatile over the sample period. This is primarily due to the observed discrepancy between the simulated series for bank $\tau$ 's capital and its coresponding real data. Given our assumption that banks always accumulate their profits as retained earnings, we observe that the growth rate of the simulated series for bank $\tau$ 's capital is higher than that observed in the real data over the sample period. The resulting excess capital, in turn, provides an additional income effect to bank $\tau$ which may outweigh the initial substitution effect from the downward trend for the interbank rate. For example, in 2001, the interbank rate fell relatively sharply, i.e. by 200 basis points. Given the resulting dominant substitution effect, we observe that bank $\tau$ 's interbank borrowing increases considerably as compared to the real data. However, in 2003, when the interbank rate fell by only 25 basis point, the implied substitution effect is not strong enough to outweigh the corresponding income effect arising from higher capital, causing bank $\tau$ 's interbank borrowing to decrease relatively more compared with the real data.

\footnotetext{
${ }^{20}$ We observe that the real data for banks $\gamma$ and $\delta$ are relatively more volatile compared to that of bank $\tau$. This is mainly because the former two represent individual banks whereas the latter is the aggregate of the remaining banks in the banking sector. The aggregation process for bank $\tau$ implies that various idiosyncracies associated with individual banks cancel out.
} 


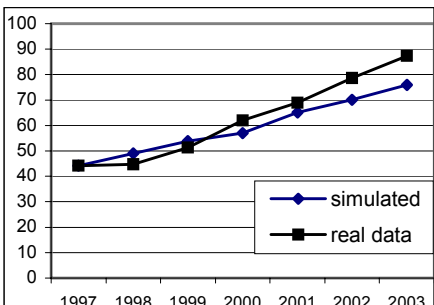

$\begin{array}{lllllll}1997 & 1998 & 1999 & 2000 & 2001 & 2002 & 2003\end{array}$

Bank $\tau$ 's loans

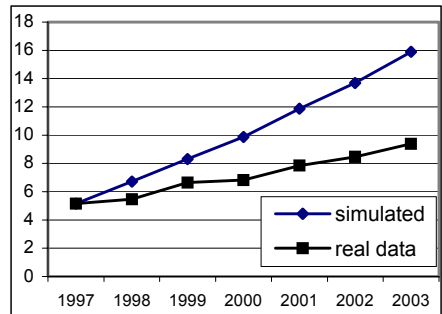

Bank $\tau$ 's capital

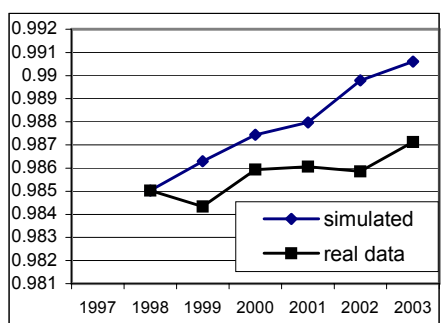

$\begin{array}{lllll}1997 & 1998 & 1999 & 2000 & 2001 \\ 2002 & 2003\end{array}$

Mr. $\theta$ 's repayment rate to bank $\tau$

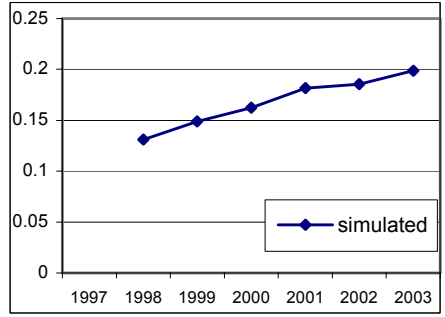

Bank $\tau$ 's CAR ratio

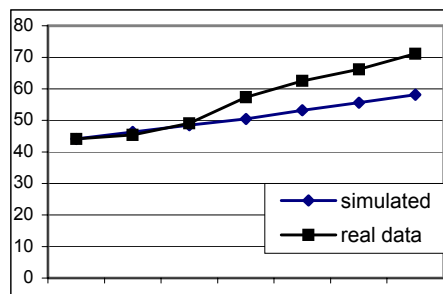

$\begin{array}{lllllll}1997 & 1998 & 1999 & 2000 & 2001 & 2002 & 2003\end{array}$

Bank $\tau$ 's deposits

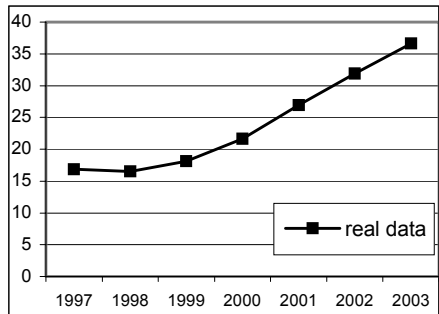

Bank $\tau$ 's market book

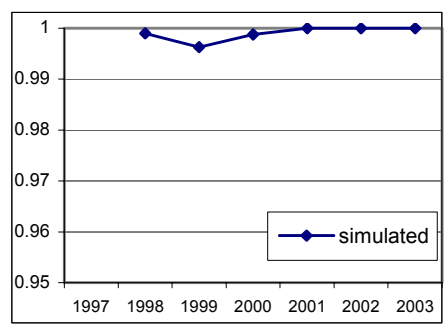

Bank $\tau$ 's repayment rate

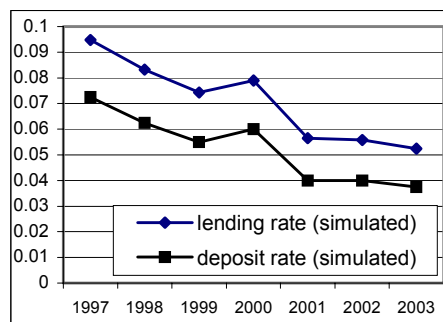

Bank $\tau$ 's lending and deposit rates

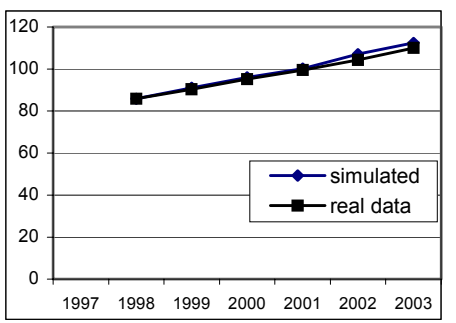

GDP

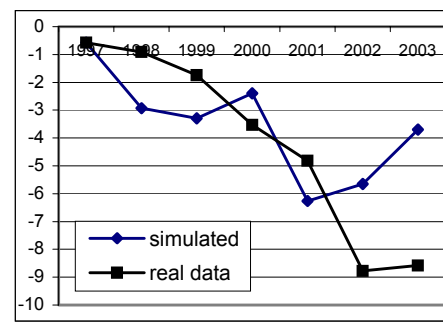

Bank $\tau$ 's net interbank lending

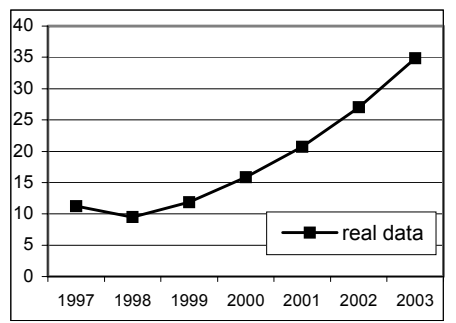

Bank $\tau$ 's 'others'

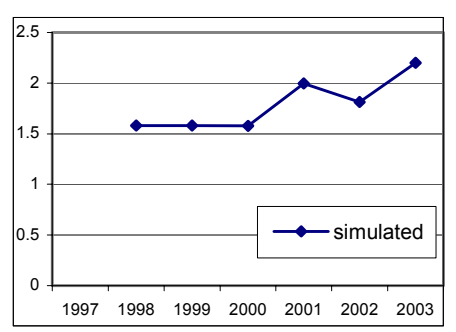

Bank $\tau$ 's profits

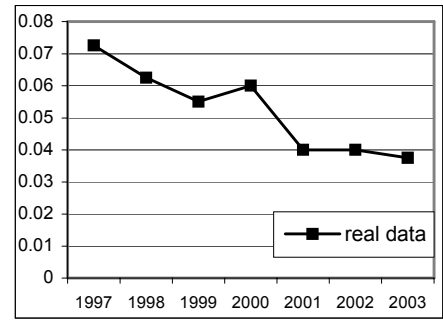

the interbank rate

Figure 2: Simulation results vs. real data 
The observed upward trend in the simulated series of bank $\tau$ 's capital implies that bank $\tau$ 's captal to asset ratio consistently increases over the sample period. Moreover, higher GDP together with increased aggregate credit supply in the economy cause Mr. $\theta$ to repay more on his loan obligations with bank $\tau$ over the period, though its rate of growth is slightly greater that suggested by the real data. Finally, the simulated series for bank $\tau$ 's repayment rate fell slightly in 1999, compared to that of the previous period, and continuously increased from then on, reaching $100 \%$ repayment rate in 2001. The reason for the observed fall in 1999 is due to the slight fall in 'others' item in the previous period. This implies that bank $\tau$ had less funds to invest in that period. So, it rationally took on a slightly riskier position, i.e. raising the probability of default slightly, in both states of the next period in order to support its corresponding expected profitability.

\section{Conclusion}

In Goodhart, Sunirand and Tsomocos (2003), we proposed a new approach to analyse financial fragility. This approach has both rigorous and advanced microfoundations, as it incorporates dynamic interaction among heterogeneous banks and investors, endogenous default, multiple credit and deposit markets and a number of financial assets. Yet, as shown in Goodhart, Sunirand, and Tsomocos (2004b), it is simple enough to be calibrated against real data at a specific point in time, and to be implemented as a stress-testing tool for banks. Moreover, we show in Goodhart, Sunirand, and Tsomocos (2004a) that a multitude of comparative statics experiments can be conducted. For example, the interactions of monetary and regulatory policies, and their relationship to financial fragility, can be analytically assessed, including the consequences for welfare.

In this paper, we confirm the relevance and validity of our approach by showing that it can replicate the time series properties of U.K. banking data satisfactorily. We do so by extending the model to an infinite horizon setting, wherein the horizon over which a bank manager optimises is shown to be finite. So, we claim that our approach is well-suited as a tool to analyse financial fragility in the UK, or in principle any other, banking system not only because it allows contagion effects between heterogeneous agents to operate actively in equilibrium but also because it can illuminate how such effects may get amplified and propagated over time.

\section{References}

[1] Bhattacharya, Sudipto, Charles A. E. Goodhart, Pojanart Sunirand, and Dimitrios P. Tsomocos, D.P. (2003). "Relative Performance, Banks and Sequential Contagion." mimeo, University of Oxford.

[2] Catarineu-Rabell, Eva, Patricia Jackson, and Dimitrios P. Tsomocos. (2003). "Procyclicality and the New Basel Accord-Banks' Choice of Loan Rating System." Economic Theory (forthcoming).

[3] Chrystal, Alex, and Paul Mizen. (2003). "Consumption, Money, and Lending: A Joint Model for the UK Household Sector." Journal of Money Credit and Banking (forthcoming). 
[4] Dubey, Pradeep, and Martin Shubik. (1978). "The Non-Cooperative Equilibria of a Closed Trading Economy with Market Supply and Bidding Strategies." Journal of Economic Theory 17, 1-20.

[5] Elsinger, Helmut, Alfred Lehar, and Martin Summer. (2003). "Risk Assessment for Banking Systems." Oesterreichische Nationalbank (Austrian National Bank) Working Paper no. 79 .

[6] Goodhart, Charles A.E., Pojanart Sunirand, and Dimitrios P. Tsomocos. (2003). "A Model to Analyse Financial Fragility." Oxford Financial Research Centre Working Paper No. 2003 fe13.

[7] Goodhart, Charles A.E., Pojanart Sunirand, and Dimitrios P. Tsomocos. (2004a). "A Model to Analyse Financial Fragility: Applications." Journal of Financial Stability, 1(1).

[8] Goodhart, Charles A.E., Pojanart Sunirand, and Dimitrios P. Tsomocos. (2004b), "A Risk Assessment Model for Banks." Annals of Finance (forthcoming).

[9] Shubik, Martin. (1999). The Theory of Money and Financial Institutions. Cambridge, MA.: MIT Press.

[10] Shubik, Martin, and Dimitrios P. Tsomocos. (1992). "A Strategic Market Game with a Mutual Bank with Fractional Reserves and Redemption in Gold." Journal of Economics $55(2), 123-150$.

[11] Shubik, Martin, and Charles Wilson. (1977). "The Optimal Bankruptcy Rule in a Trading Economy Using Fiat Money. Journal of Economics 37, 337-354.

[12] Tsomocos, Dimitrios P. (2003a). "Equilibrium Analysis, Banking and Financial Instability." Journal of Mathematical Economics 39(5-6), 619-655.

[13] Tsomocos, Dimitrios P. (2003b). "Equilibrium Analysis, Banking, Contagion and Financial Fragility." Greek Economic Review 23(1).

[14] Tsomocos, Dimitrios P., and Lea Zicchino. (2004). "On Modelling Endogenous Default." mimeo, Bank of England. 